\title{
Favourable influence of Revised Basic Course Workshops in Medical Educational Technology on Knowledge of Teaching Learning and Assessment Methods of Participants
}

\author{
Mahajan, A.S.
}

\begin{abstract}
Objective: The objective of the study was to assess the outcome of medical education workshops in terms of their usefulness, actual and perceived knowledge gained and the utilization of teaching learning and assessment methods learnt by the participants.
\end{abstract}

Methods: Three workshops on medical education technology with a pretest and posttest immediately and at 2 and 6 months after the workshop were conducted.

Results: The scores of usefulness of workshop remained consistent in post workshop evaluations. The knowledge scores of participants in all posttest evaluations were greater than the pretest scores. However, in comparison to immediate posttest values, there was a decrease in the score at 2 months, which again increased at 6 months. Perception of utilization of teaching learning methods decreased from 0 to 6 months and perception of knowledge of assessment methods decreased at 2 and 6 months from immediate post workshop scores. The post workshop perception of, knowledge of teaching learning methods and utilization of assessment methods did not change at the end of six months.

Conclusion: The workshops were useful and increased the knowledge of teaching learning and assessment methods in participants in comparison to pre workshop value. Perception of utilization of teaching learning methods and perception of knowledge of assessment methods decreased from immediate post workshop evaluations.

Keywords: Medical education, Faculty training, Programme evaluation, Teaching methods, Assessment methods

\section{Introduction}

The medical education technology workshops aim to provide and reinforce knowledge related to the subject but whether or not the knowledge imparted is retained and for how long is a matter of speculation. Many authors have stated that the retention time is proportional to the utilization of knowledge by the participants.

Corresponding Author:

Aarti Sood Mahajan

Director Professor, Department of Physiology \& Honorary faculty of Department of Medical Education, Maulana Azad Medical College, Bahadur Shah Zafar Marg, New Delhi 110002, India.

E mail: aartis_mahajan@yahoo.co.in
In one self-reported study without objectively measured variables, an increase in evidenceinformed decision making knowledge from baseline to six months was found, but it decreased from post workshop to six months thereafter (Yost et al., 2014). In another evaluation of medical teachers training program through Kirkpatrick's model there was a significant improvement in curriculum development followed by research methods and evaluations (Masood \& Usmani, 2015). A study done in King Saud University found that the knowledge increased after the workshops and more research projects were generated but attributed the change due to many confounding factors (Abdulghani et al., 2014). However a post workshop decrease in scores related to

DOI: http://doi.org/10.4038/seajme.v13i1.59

(CC) $\begin{aligned} & \text { C SEAJME. This is an Open Access article distributed under the terms of the Creative Commons Attribution } \\ & \text { License (http://creativecommons.org/licenses/by/4.0/), which permits unrestricted use, distribution, and } \\ & \text { reproduction in any medium, provided the original author and source are credited }\end{aligned}$


curriculum and assessment and retention of knowledge related to problem based learning (PBL), communication skills and feedback is reported (Naeem, 2016).

Other studies highlight that the knowledge gained by the participants during the programs is an important determinant to assess their overall usefulness. In one such evaluation done in four medical colleges in Nepal, $57 \%$ of participants felt that the sessions on teaching learning methods were useful (Baral et al., 2007). It has been suggested that in addition to these knowledge transfer workshops, booster sessions should be undertaken to maintain enthusiasm and to bring about a favourable change in the workplace (Steinert et al., 1995). However, it has also been observed that there exists a need to elaborate and emphasize on more skill training during these workshops (Purandare \& Vagha, 2015).

In this context, this study was planned in order to evaluate the immediate and sustained perception of the faculty about their knowledge and utilization of teaching learning and assessment methods and the usefulness of medical educational technology workshops, based on the revised basic course proposed by the medical council of India. In additional to this, the study aimed to objectively assess the knowledge gained if any, related to teaching learning and assessment methods of the faculty participating in the workshop.

\section{Material and methods}

A longitudinal, prospective, analytical follow up study, with a quasi-experimental approach and a time series experimental design was conducted in the Department of Medical Education of my institute from May 2016 to April 2017. Three identical workshops with same content for different set of participants were held from August to September 2016 as per the revised basic course of the Medical Council of India, the first conducted from 8th to 10th August 2016, the second from 30th August to 1st September 2016 and the third from 20th to 22nd September 2016 respectively. Ethical approval was obtained from the institutional ethical committee prior to conducting the workshops.

\section{Ethos of the workshop}

The three days' workshop provided a comprehensive 'hands on' training on topics related to medical education technology. It began with the concept of group dynamics, team work, goals and roles of the medical graduate. The workshop encouraged the participants to have interactive discussions and collaborations on topics related to learning domains, competencies and objectives. It also helped them understand the concept of large and small groups, interactive and innovative teaching methods and link the objectives to teaching and the assessment methods. Formative and internal assessment, skill development, self-directed learning, feedback and educational networking were other important concepts that were part of the workshop. All sessions involved two way communication methods that facilitated participation and faculty development.

\section{Participants and procedure of the study}

Faculty members from various medical colleges attached to my institute which is a regional centre for this course had enrolled to attend the basic course in medical education, volunteered and gave an informed written consent. A single response MCQ pretest based on the workshop's content related to teaching learning and assessment methods was conducted. Thereafter, the workshop was continued as per schedule. The posttests were then conducted at three different times, immediately after the workshop and this was designated as 0 month data. The same procedure was repeated at 2 and 6 months to check the reliability of our results and to ensure that the changes were long term, and that the study was completed within the time frame of one year.

\section{The questionnaire}

A validated and pilot tested questionnaire was used. It included questions related to usefulness of the workshop, knowledge of teaching learning and assessment methods, perception of knowledge and utilization of teaching learning and assessment methods. The usefulness of the workshop was assessed on a 5 point Likert type items ranging from 'strongly disagree' to 'strongly agree' with 20 items, relating to different sessions and one for overall usefulness of the workshop. To evaluate the knowledge of teaching learning and assessment methods, 20 single response MCQ were asked. Perceived knowledge and utilization of teaching learning and assessment methods was also estimated on a 5 point Likert scale which ranged from strongly disagree to strongly agree. It had 4 items each related to knowledge of teaching learning methods and their utilization by the participants and had 6 
items each related to the knowledge of assessment methods and their utilization. The pre-workshop evaluation and the immediate post workshop evaluation questionnaire was in a physical form while those followed were mainly in the online web based format.

\section{Validation of questionnaire}

The questionnaire was validated as per the standard procedures (Artino et al., 2014). Twenty four faculty from various departments of the institute were involved. Of these, 6 were involved in making the questionnaire, 8 in expert validation and 10 participated in the pilot study. The content validity ratio was 1.0. Average congruency percentage was $99.2 \%$. The CVI/UA scale was calculated as 0.96 and the $\mathrm{CVI} /$ Average scale was calculated as 0.99 . The Cronbach alpha was 0.939 .

\section{Protocol of follow up of participants}

Groups were formed separately for each set of participants on the e-mail and social media applications. This was done to ensure regular connect with them and to assist in the compliance of the study.

\section{Statistical Analysis}

Quantitative analysis of data was done using SPSS-23 version. The $t$ test was used for comparing scores of knowledge. The chisquare test, paired sample correlations and ttest was used for comparison of usefulness between 0, 2 and 6 months. The Pearson's correlation was calculated between parameters mentioned.

\section{Results}

There were 72 participants initially (26, 26 and 20 in first, second and third workshop) which decreased to 69 at 2 months and 63 participants $(24,22,17$ in each workshop respectively) at the end of 6 months. Maximum number of participants $(40 \%)$ were in the age group of 40-49 years. The gender distribution was $54 \%$ male and $46 \%$ female. The distribution with respect to designation was $58 \%$ professors, $28 \%$ associate professors and $14 \%$ assistant professors. $68 \%$ of the participants were part of the Medical Education Unit (MEU) of their institution.

The expertise varied, $10 \%$ had up to 5 years, $25 \%$ had $6-10$ years, $21 \%$ had $11-15$ years, $21 \%$ had $16-20$ years, $7 \%$ had about $21-25$ years and $16 \%$ had more than 25 years of teaching experience. The participants (75\%) reported that their attendance of the workshop was both voluntary and an institutional requirement, $6 \%$ were only voluntarily attending and $19 \%$ wrote that they were attending due to institutional requirement only.

\section{Workshop usefulness}

The scores on Likert scale at 0,2 and 6 months respectively are shown in (Table 1 ). The paired sample test showed that the usefulness of workshops remained similar from 0-6 months. Usefulness scores of mode of responses on Likert items are shown in (Table 2). The chisquare test done to evaluate the difference in usefulness at the three intervals showed a significance difference $(p=0.046)$. It can be seen from Table 2 that usefulness of some sessions showed a decrease in the mode of responses. However paired sample correlations between 0,2 and 6 months were also significant with $p=0.000$ and it should be noted that most of the responses are among 'agree' and 'strongly agree' across the period of observation.

Table 1: Workshop Usefulness Score of the Workshops at 0, 2 And 6 Months Post Workshop

\begin{tabular}{ccccc}
\hline $\begin{array}{c}\text { Workshop } \\
\text { usefulness }\end{array}$ & $\begin{array}{c}\text { Post workshop } \\
\text { 0 months } \\
\text { (Mean } \pm \text { SD) }\end{array}$ & $\begin{array}{c}\text { Post workshop } \\
\text { 2 months } \\
\text { (Mean } \pm \text { SD) }\end{array}$ & $\begin{array}{c}\text { Post workshop } \\
\mathbf{6} \text { months } \\
\text { (Mean } \pm \text { SD) }\end{array}$ & p value \\
\hline Usefulness score & $88.13 \pm 8.169$ & $87.63 \pm 9.699$ & $86.02 \pm 10.786$ & 0 to 2 months $=0.654$ \\
\cline { 4 - 5 } & & & 0 to 6 months $=0.075$ \\
\hline
\end{tabular}

SD: Standard deviation values $p<0.05$ is significant. 
Table 2: Usefulness Score of Individual Sessions of the Workshops at 0, 2 and 6 Months after the Workshops

\begin{tabular}{lccc}
\hline \multicolumn{1}{c}{ Session name } & $\begin{array}{c}\text { Post workshop } \\
\text { 0 months }\end{array}$ & $\begin{array}{c}\text { Post workshop } \\
\text { 2months }\end{array}$ & $\begin{array}{c}\text { Post workshop } \\
\text { 6months }\end{array}$ \\
\hline Ice breaking, Group dynamics & 4 & 4 & 4 \\
System approach, adult learning & 4 & 4 & 4 \\
Goals, roles, competency & 4 & 4 & 4 \\
IMG, goals, roles, competency & 4 & 4 & 4 \\
Learning domains & 5 & 5 & 4 \\
Objective writing & 5 & 4 & 4 \\
Linking TLM to objectives \& competency & 5 & 5 & 5 \\
Interactive, innovative TLM \& Media & 5 & 5 & 5 \\
Writing lesson plan & 5 & 5 & 5 \\
Effective clinical, practical skill teaching & 5 & 5 & 5 \\
Teaching attitudinal domain & 5 & 4 & 4 \\
Assessment & 5 & 5 & 4 \\
Essay Type, SAQ, MCQ & 5 & 4 & 4 \\
Assessment of practical, clinical skills & 5 & 5 & 5 \\
Assessment of attitudinal domain & 5 & 4 & 4 \\
Assessment to TLM, objectives, competency & 5 & 4 & 4 \\
Self-directed learning & 4 & 5 & 4 \\
Feedback & 4 & 5 & 4 \\
Educational networking & 4 & 4 & 4 \\
Overall workshop & 5 & 5 & 5 \\
\hline
\end{tabular}

IMG: Indian Medical Graduate, TLM: Teaching Learning Methods, SAQ: Short Answer Questions, MCQ: Multiple Choice Questions: All values reported are mode values: Values represent the mode value of scores on Likert scale: 1- Strongly disagree, 2-disagree, 3- neutral, 4- Agree, 5- Strongly agree.

Knowledge score of teaching learning and assessment methods

The scores of MCQ are shown in (Table 3). A significant increase in post workshop knowledge scores was seen at 0,2 and 6 months when compared to pretest scores. However, the scores decreased from post workshop 0 to 2 months and increased thereafter at 6 months. The changes between post workshops 0-6 months were not significant. All correlation of MCQ scores from pre workshop to post workshop; post workshop 0 to 2 and 6 months, and between 2 and 6 months were significant.

Table 3: Scores of Knowledge of Teaching Learning and Assessment Methods

\begin{tabular}{|c|c|c|c|c|}
\hline $\begin{array}{l}\text { Pre workshop } \\
\text { Mean } \pm \text { SD }\end{array}$ & $\begin{array}{c}\text { Post workshop } \\
0 \text { months } \\
\text { Mean } \pm \text { SD }\end{array}$ & $\begin{array}{c}\text { Post workshop } \\
2 \text { months } \\
\text { Mean } \pm \text { SD }\end{array}$ & $\begin{array}{c}\text { Post workshop } \\
6 \text { months } \\
\text { Mean } \pm \text { SD }\end{array}$ & $p$ value \\
\hline \multirow{6}{*}{$9.37 \pm 2.813$} & \multirow{6}{*}{$12.65 \pm 2.37$} & \multirow{6}{*}{$11.59 \pm 2.849$} & \multirow{6}{*}{$12.24 \pm 2.493$} & $\begin{array}{l}\text { Pre to Post } 0 \\
\text { months }=0.000\end{array}$ \\
\hline & & & & $\begin{array}{l}\text { Pre to Post } 2 \\
\text { months }=0.000\end{array}$ \\
\hline & & & & $\begin{array}{l}\text { Pre to Post } 6 \\
\text { months }=0.000\end{array}$ \\
\hline & & & & $\begin{array}{l}\text { Post } 0 \text { to Post } 2 \\
\text { months }=0.002\end{array}$ \\
\hline & & & & $\begin{array}{l}\text { Post } 0 \text { to Post } 6 \\
\text { months }=0.209\end{array}$ \\
\hline & & & & $\begin{array}{l}\text { Post } 2 \text { to Post } 6 \\
\text { months }=0.027\end{array}$ \\
\hline
\end{tabular}


Perception of knowledge of teaching learning and assessment methods

The scores of perception of knowledge of teaching learning and assessment methods is shown in (Table 4). The scores of perception of knowledge of teaching learning methods remained constant throughout the period. The scores of perception of knowledge of assessment methods decreased at 2 months and 6 months from post workshop 0 months. The change in the frequency of responses from 0 to 6 months is shown in (Figure 1). The correlation of scores of perception of knowledge of teaching learning and assessment methods from 0 to 2, 0 to 6 months, and 2 to 6 months were all significant.

Table 4: Scores of Perception of Knowledge and Utilization of Teaching Learning and Assessment methods

\begin{tabular}{|c|c|c|c|c|}
\hline Perception score & $\begin{array}{c}\text { Post workshop } \\
0 \text { months } \\
\text { Mean } \pm \text { SD }\end{array}$ & $\begin{array}{c}\text { Post workshop } \\
2 \text { months } \\
\text { Mean } \pm \text { SD }\end{array}$ & $\begin{array}{c}\text { Post workshop } \\
6 \text { months } \\
\text { Mean } \pm \text { SD } \\
\end{array}$ & $p$ value \\
\hline $\begin{array}{c}\text { Perception of } \\
\text { knowledge of Teaching } \\
\text { Learning Methods }\end{array}$ & $16.86 \pm 1.916$ & $17.02 \pm 1.827$ & $16.78 \pm 1.896$ & $\begin{array}{l}0 \text { to } 2 \text { months }=0.523 \\
0 \text { to } 6 \text { months }=0.770 \\
2 \text { to } 6 \text { months }=0.286\end{array}$ \\
\hline $\begin{array}{l}\text { Perception of utilization } \\
\text { of Teaching Learning } \\
\text { Methods }\end{array}$ & $17.40 \pm 2.413$ & $17.02 \pm 1.871$ & $16.71 \pm 2.358$ & $\begin{array}{l}0 \text { to } 2 \text { months }=0.285 \\
0 \text { to } 6 \text { months }=0.008 \\
2 \text { to } 6 \text { months }=0.353\end{array}$ \\
\hline $\begin{array}{c}\text { Perception of } \\
\text { knowledge of } \\
\text { Assessment Methods }\end{array}$ & $26.54 \pm 2.729$ & $25.22 \pm 3.050$ & $25.10 \pm 3.591$ & $\begin{array}{l}0 \text { to } 2 \text { months }=0.001 \\
0 \text { to } 6 \text { months }=0.004 \\
2 \text { to } 6 \text { months }=0.805\end{array}$ \\
\hline $\begin{array}{l}\text { Perception of utilization } \\
\text { of Assessment Methods }\end{array}$ & $25.98 \pm 3.051$ & $25.16 \pm 3.033$ & $25.25 \pm 3.267$ & $\begin{array}{l}0 \text { to } 2 \text { months }=0.051 \\
0 \text { to } 6 \text { months }=0.136 \\
2 \text { to } 6 \text { months }=0.835\end{array}$ \\
\hline
\end{tabular}

SD: Standard Deviation ${ }^{*} p<0.05$ is significant

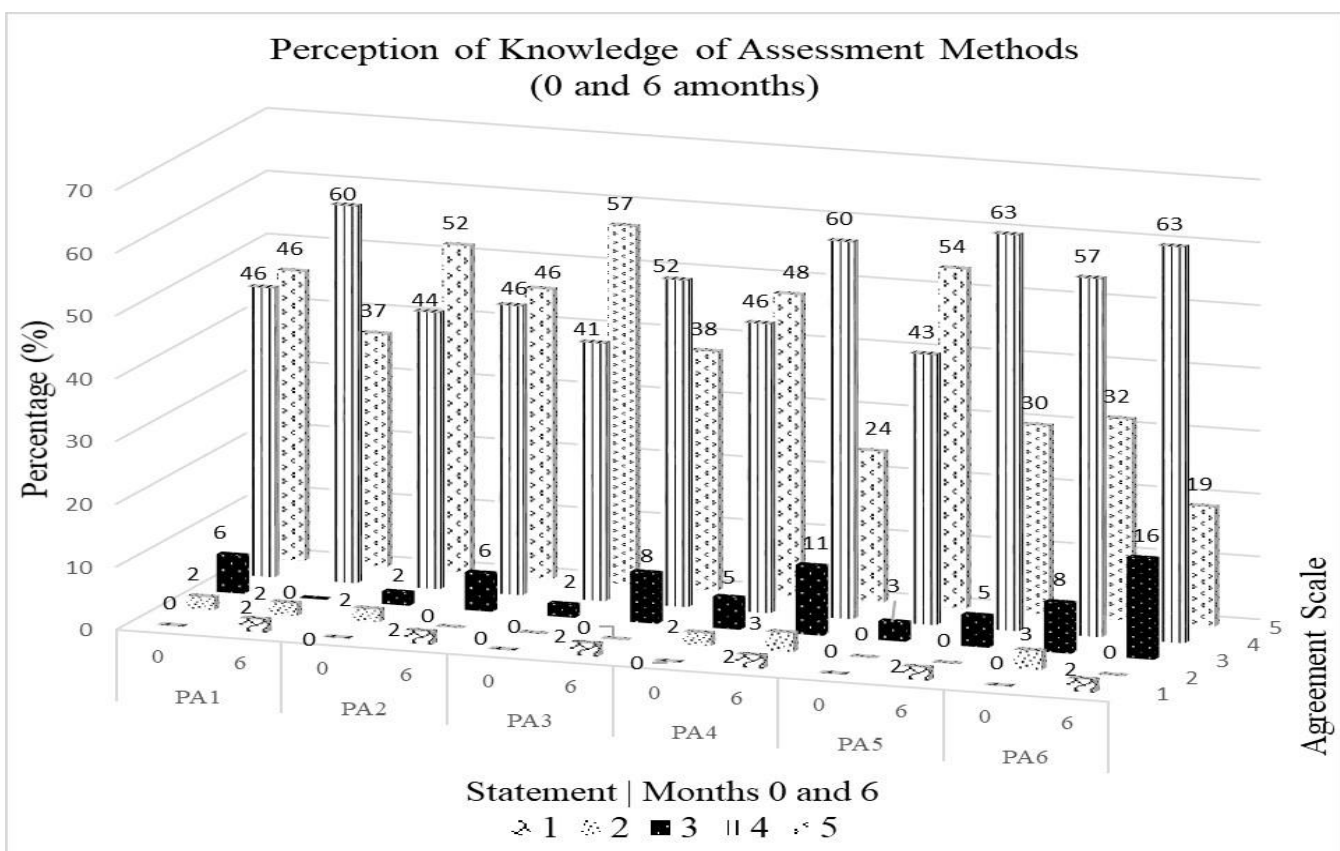

Note: PA1 - Essay type question, PA2 - Short answer questions, PA3 - Multiple choice questions (MCQ), $P A 4$ - Item Analysis of MCQ, PA5 - Practical/clinical skills, PA6 - Attitudinal domains 1-Strongly disagree, 2-Disagree, 3- Neutral, 4- Agree, 5- Strongly agree

Figure 1: The percentage of participants giving responses 1-5 on Likert scale (agreement scale) for perception of assessment (PA) methods at post workshop 0 and 6 months 


\section{Actual knowledge and perception of knowledge}

All correlations between actual knowledge scores of MCQ and perception of knowledge at 0,2 and 6 months were not significant.

\section{Perception of utilization of teaching and assessment methods}

The scores of perception of utilization of teaching learning methods, however, decreased from 0 to 6 months (Table 4). The perception of utilization of assessment methods did not change during the intervention period. Correlation of scores of perception of utilization of teaching learning and assessment methods from 0 to 6 and 2 to 6 were all significant except for perception of utilization of teaching learning methods from post workshop 0 to 2 months $(p=0.202)$.

\section{Discussion}

The workshops carried out in my institute were evaluated in this study in terms of their usefulness to faculty, perception of usefulness of different topics included and whether they increased the knowledge of medical education technology. The usefulness score suggests that the workshops were useful consistently after the workshop indicating the reliability of the responses. Previous studies have shown similar results (Masood \& Usmani, 2015; Baral et al., 2007). This study was different from previous studies as evaluation was done three times to get a comprehensive, reliable and sustained feedback and not an initial euphoric kneejerk reaction.

This study also showed that the pre-workshop score average was less than $50 \%$, and knowledge of teaching learning methods and assessment methods increased in all post workshop evaluations. On analysis, the increase immediate post workshop was not sustained at 2 months but was noticed at 6 months probably due to other confounding factors. A similar pattern was obtained in a study in Nepal where improvement in beginning and end of workshop was reported (Baral et al., 2011). A gain in knowledge, skills and behaviour are some of the aspects of outcome of these workshops studied (Yost et al., 2014; Abdulghani et al., 2014; Cansever et al., 2014; Ghazvini et al., 2014; Paul et al., 2015). A score based gain in knowledge showed increase in fields of objective assessment, OSPE, OSCE, structured oral viva, long case, mini clinical evaluation exercise and MCQ (Gaur et al.,
2015). Similarly hospital consultants showed that there was improvement in their presentation skills, educational supervision, utilizing ideas and learning (Whitehouse, 1997). Some studies have analysed the long term impact of these workshops for a period of 3 months to two years (Gaur et al., 2015; Nagdeo \& Chari 2014; Whitehouse, 1997).

It has been suggested that only those skills which are applied are retained (Naeem, 2016). The lack of effective learning of skills, lack of time to use them and limited resources are some lacunae that decrease the utility of these workshops (Whitehouse, 1997), and their regular upgradation for the reinforcement of psychomotor skills and a refresher course of one day are some improvements suggested (Purandare \& Vagha, 2015). However, other studies have reported a positive impact of these training courses stating that the faculty used the skills learnt and it improved their interaction with students (Yolsal et al., 2003; Godfrey et al., 2004).

In this study, the scores of perception of knowledge of teaching learning methods remained similar in all observations but the perception of their utilization decreased from post workshop 0 to 6 months. This suggests that the faculty felt that they knew about the methods but were not using them. In case of the assessment methods, the perception of knowledge decreased from the post workshop values in both the 2 and 6 month observations. However, the perception of utilization of assessment methods did not show any change. The lack of correlation of actual and perceived knowledge confirms the need for refresher courses in medical education technology and a possible follow up for all participants.

The most appropriate outcome of these faculty development programs workshop should be students rating of teaching behaviour of faculty and actual learning outcome of the students (Hodgson \& Wilkerson, 2014; Sathe, 2016). This would relate to Kirkpatrick's fourth level of evaluation. Nevertheless, a positive change in behaviour and attitude towards teaching, increased knowledge of educational principles, gain in teaching and pedagogical skills, educational involvement and establishing a collegiate network and lasting impact are documented benefits that suggest the usefulness and requirements of these workshops (Steinert et al., 2006; Persellin \& Goodrick, 2010). 
In this study, most of the participants were a part of the MEU of their institutes, were professors and had variable duration of teaching experience. In addition, there could be many confounding factors which may have influenced the interest and outcome of this study. These include additional workshops attended by faculty, material read or discussed with other faculty, renewed interest in the topic, varying priorities and the level of seriousness in answering at different time periods. As these factors have not been addressed, the exact reason cannot be commented upon. However, it is a positive response that increases the credibility of these workshops. It was pointed out in a study that in such workshops, the internal validity can be questioned if participants act as their own control, external validity is questionable as in the method most of the participants were professionals, many belonging to the medical education unit (Sherbino et al., 2006).

All these points are the constraints or lacunae of this study. However the years of professional experience varied and since repeated or continuous exposure or self - learning cannot be stopped, this is a common confounding factor in all such studies. Taking a student's feedback, whether they benefit, do faculty teach better, use more skills and perform better and ultimately how this benefits the society at large, is the future scope of this study and a recent study has shown that students want passionate teachers, willing to sacrifice and open to feedback (Lee et al., 2018). In this endeavour, the faculty development programs should be need based, flexible and global in their approach, their content should be related to relevant problems and specific objectives and they should develop from a teachers' training to a professional's development program (Bansal \& Supe, 2007; Adkoli \& Sood, 2009).

In conclusion, this evaluation of the workshops on medical education technologies have shown that the knowledge increased, immediately after the workshops, decreased at 2 months but reverted back at 6 months. The perception of this knowledge did not correlate with the actual scores. The perception of knowledge of assessment methods decreased from post workshop to 2 and 6 months. The perception of utilization of teaching learning methods decreased over the period of six months. The study builds on previously established usefulness of these workshops and gives us a positive feedback to reinforce our commitment to provide state of the art training in medical education technology. It provides additional information that actual knowledge of teaching, learning and assessment methods increases as a result of these workshops although the perception and utilization of knowledge of teaching and learning and methods may vary with the passage of time.

\section{Acknowledgement}

I wish to acknowledge the guidance and cooperation of the Head of my institute and head of department of medical education, the help of faculty members from different departments of my institute for validation of my questionnaire and technical staff for assistance. I also thank my participants for their time and enthusiasm, my batch and senior FAIMER fellows for their feedback on my work.

\section{References}

Abdulghani, H.M., Shaik, S.A., Khamis, N., Al-Drees, A.A., Irshad, M., Khalil, M.S., Alhaqwi, A.I. \& Isnani, A. (2014) Research methodology workshops evaluation using the Kirkpatrick's model: translating theory into practice, Medical Teacher, 36(Sup I), pp. S24-S29

Adkoli, B.V. \& Sood, R. (2009) Faculty development and medical education units in India: a survey, National Medical Journal of India, 22, 1, pp. 2832

Artino Jr, A.R., La Rochelle, J.S., Dezee, K.J. \& Gehlbach, H. (2014) Developing questionnaire for educational research. AMEE Gide No: 87, Medical Teacher, 36, pp. 463-474

Bansal, P. \& Supe, A. (2007) Training of medical teachers in India: Need for change, Indian Journal of Medical Sciences, 61, 8, pp. 478-484

Baral, N., Gautam, A., Lamsal, M., Paudel, B.H., Lal Das, B.K. \& Aryal, M. (2011) Effectiveness of teachers' training in assessment techniques: participants' perception, Kathmandu University Medical Journal, 9, 35, pp. 189-192

Baral, N., Paudel, B.H, Das, B.K., Aryal, M., Das, B.P., Jha, N. \& Lamsel, M. (2007) An evaluation of training of teachers in medical education in four medical schools of Nepal, Nepal Medical College Journal, 9, 3, pp. 157-161

Cansever, Z., Acemoglu, H., Avsar, U.Z., Akturk, Z., Set, T., Avsar, U. \& Cayir, Y. (2014) What do trainers think about trainer training course? Journal of Pakistan Medical Association, 64, 5, pp. 491-495

Gaur, A., Bansal, A. \& Bindal, J. (2015) Impact of basic medical education on medical teachers, Journal of Medical Research, 1, 3, pp. 95-103 
Ghazvini, K., Mohammadi, A. \& Jalili, M. ( 2014) The impact of the faculty development workshop on educational research abilities of faculties in Mashhad University of Medical Science, Future of Medical Education Journal, 4, 4, pp. 24-27

Godfrey, J., Dennick, R. \& Welsh, C. (2004) Training the trainers: do teaching courses develop teaching skills? Medical Education, 38, 8, pp. 844-847

Hodgson, C.S. \& Wilkerson, L.A. (2014) Faculty development for teaching improvement. In: Steinert $Y$ editor, Faculty Development in the Health Professions: A Focus on Research and Practice, Innovation and Change in Professional Education, Springer Science Business Media Dordrecht, pp. 29-52

Lee, S.S, Dong, C., Yeo, S.P., Gwee, M.C.E. \& Samarasekera, D.D. (2018) Impact of faculty development programs for positive behavioural changes among teachers: a case study, Korean Journal of Medical Education, 30, 1, pp. 11-22

Masood, R.Q. \& Usmani, M.A.W. ( 2015) Evaluation of medical teachers training program through Kirkpatrick's model, Khyber Medical University Journal, 7, 2, pp. 76-80

Naeem, N. (2016) Which knowledge and skills do participants retain after attending medical education training workshops? Creative Education, 7, pp. 870-877

Nagdeo, N. V. \& Chari, S. (2014) Basic Workshop for medical teachers: effectiveness and impact, National Journal of Integrated Research in Medicine, 5, 2, pp. 107-114

Paul, U.K., Ghosh, S., Ghosh, D. \& Bandyopadhay, A. (2015) Impact of medical education technology workshops in a rural medical college of Bihar: A questionnaire Study, International Journal of Scientific Study, 3, 5, pp. 5-9

Persellin, D. \& Goodrick, T. (2010) Faculty development in higher education, Long term impact of a summer teaching and learning workshop, Journal of the Scholarship of Teaching and Learning, 10, 1, pp. 1-13
Purandare, S. \& Vagha, S. (2015) Perception of faculty who have undergone the basic course of medical education technology about the module of basic course workshop by medical council of India, Journal of Health Science Education, 2, 1, pp. 7-12

Sathe, M.J. (2016) Evaluation of medical education unit trained teachers by students, International Journal of Healthcare and Biomedical research, 4, 4, pp. 58-63

Sherbino, J., Frank, J., Lee, C. \& Bandiera, G. (2006) Evaluating "ED STAT!" A novel and effective faculty development program to improve emergency department teaching, Academic Emergency Medicine, 13, pp. 1062-1069

Steinert, Y., Lawn, N., Handfield -Jones, R., Nasmith, L., Lussier, D. \& Levitt, C. (1995) Orientation for new teachers. Workshop on clinical teaching skills, Canadian Family Physician, 41, pp. 79-85

Steinert, Y., Mann, K., Centeno, A., Dolmans, D., Spencer, J., Celula, M. \& Prideaux, D. (2006) A systematic review of faculty development initiatives designed to improve teaching effectiveness in medical education, BEME Guide no: 8, Medical Teacher, 28, 6, pp. 497526

Whitehouse, A. (1997) Warwickshire consultants 'training the trainers' course, Postgraduate Medical Journal, 73, pp. 35-38

Yolsal, N., Bulut, A., Karabey, S., Ortayli, N., Bahadir, G. \& Aydin, Z. (2003) Development of training of trainers programmes and evaluation of their effectiveness in Istanbul, Turkey, Medical Teacher, 25, 3, pp. 319-324

Yost, J., Ciliska, D. \& Dobbins M. (2014) Evaluating the impact of an intensive education workshop on evidence-informed decision making knowledge, skills, and behaviours: a mixed methods study, BMC Medical Education, 14, 13 